\title{
Rationale and initial experience with the Tri-Ad Adams tricuspid annuloplasty ring
}

Federico Milla, MD, Javier G. Castillo, MD, Robin Varghese, MD, Joanna Chikwe, MD, Anelechi C. Anyanwu, MD, and David H. Adams, MD

Controversy exists regarding the indication and method of repair of functional tricuspid regurgitation (TR) in patients undergoing mitral valve surgery. Whereas the American College of Cardiology/American Heart Association guidelines recommend tricuspid repair in the setting of severe TR, tricuspid repair is advised for less than severe TR in the setting of annular dilation or pulmonary hypertension. Although multiple repair strategies exist, the use of a ring annuloplasty (semirigid remodeling rings vs flexible bands) is the preferred method of therapy to avoid short- and long-term recurrence of TR. The new Tri-Ad Adams annuloplasty ring combines elements of semirigid and flexible bands that will not only allow for annular remodeling in the region of the right ventricular free wall but also potentially reduce injury to the conduction system with its flexible and "open" ends. In this article, we discuss the rational for an aggressive approach to functional tricuspid regurgitation, and show our initial clinical experience with the Tri-Ad Adams annuloplasty ring. ( $\mathrm{J}$ Thorac Cardiovasc Surg 2012;143:S71-3)

Functional tricuspid regurgitation (TR) is commonly observed in patients with left-sided valvular disease, particularly in the setting of chronic severe mitral regurgitation or stenosis. If left untreated, the progression of clinically silent or less than severe TR to symptomatic severe TR can compromise the long-term surgical outcomes of mitral valve surgery. ${ }^{1}$ Therefore, although the concomitant treatment of asymptomatic tricuspid disease at mitral surgery

From the Department of Cardiothoracic Surgery, Mount Sinai School of Medicine, New York, NY.

Disclosures: Federico Milla, Javier Castillo, Robin Varghese, Joanna Chikwe, Anelechi C. Anyanwu and David H. Adams have nothing to disclose with regard to commercial support.

Presented at The American Association for Thoracic Surgery Mitral Conclave, New York, New York, May 5-6, 2011

Received for publication Aug 8, 2011; accepted for publication Nov 8, 2011; available ahead of print Jan 27, 2012.

Address reprints to David H. Adams, MD, Department of Cardiothoracic Surgery, The Mount Sinai Medical Center, 1190 Fifth Avenue, New York, NY 10029-102 (E-mail: David.Adams@msnyuhealth.org).

$0022-5223 / \$ 36.00$

Copyright (C) 2012 by The American Association for Thoracic Surgery

doi:10.1016/j.jtcvs.2011.11.015 remains controversial, especially in the setting of degenerative mitral valve disease, the American College of Cardiology/American Heart Association guidelines for the management of patients with valvular heart disease advocate for a more aggressive approach in the presence of significant tricuspid annular dilation or pulmonary hypertension. ${ }^{2}$

The current surgical treatment of functional TR is tricuspid valve annuloplasty repair. The incidence of predischarge residual moderate TR after tricuspid repair with nonannuloplasty techniques (De Vega or Kay) has been reported to be as great as $20 \% .^{3}$ In contrast, the implantation of tricuspid annuloplasty devices has been demonstrated to provide the best mid- and long-term outcomes after tricuspid repair. ${ }^{1,4,5}$ In this context, previous tricuspid annuloplasty devices have either focused on annular remodeling (rigid or semirigid rings) $)^{1,5}$ or annular size reduction that preserves annular motion (flexible rings or bands). ${ }^{6,7}$

The native tricuspid annulus is a 3-dimensional nonplanar structure with high (anteroposterior) and low
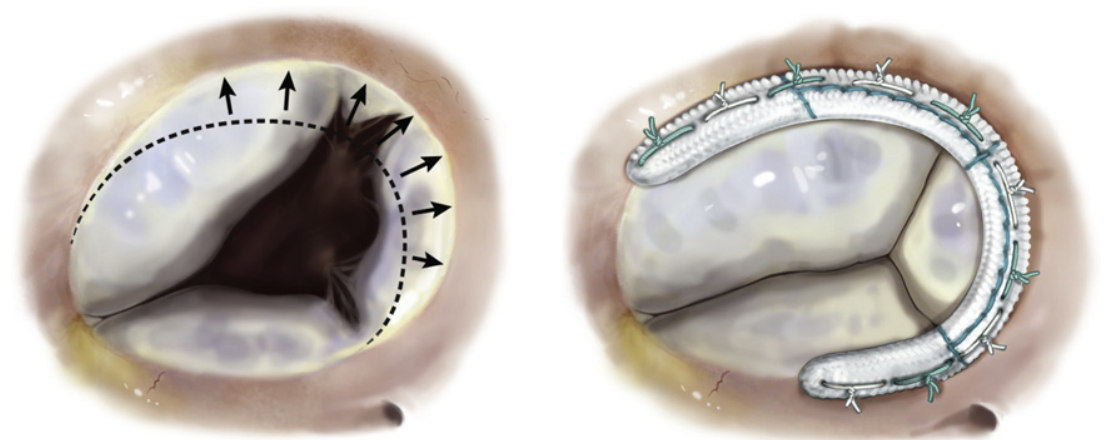

FIGURE 1. Tri-Ad Adams tricuspid annuloplasty ring. Note the green markers that correspond to the location of the semirigid portion of the ring (end markers) and the anteroposterior commissure (middle marker). 


\section{Abbreviation and Acronym \\ $\mathrm{TR}=$ tricuspid regurgitation}

(mediolateral) points that can become larger, flatter, and circular, leading to functional TR. Hence, the ideal annuloplasty device should take into account the geometric changes and restore or allow the normal 3-dimensional elliptical shape of the annulus to reduce leaflet stress and possible tethering. It should also focus the remodeling along the area of maximal annular dilation and along the right ventricular free wall margin, yet have an "open" design to protect the conduction system as much as possible. ${ }^{8}$ Ideally it would also have "flexibility" in the areas of 3-dimensional motions or in areas prone to ring dehiscence, especially along the membranous septum. ${ }^{3}$

\section{TRI-AD ADAMS TRICUSPID ANNULOPLASTY RING}

The Tri-Ad Adams tricuspid annuloplasty ring design combines the concept of annular remodeling with rigid rings, while preserving the annular motion of the flexible bands (Figure 1). Flexible ends are combined with a semirigid mid-portion along the middle portion of the annuloplasty device. The stiff assembly consists of a 71-mm diameter polished wire covered by a thin-walled silicone elastomer tube. A braided polyester fabric with 3 radial green marks forms the body of the ring. The first mark indicates the end of the stiffener section at the septal/posterior commissure. The second mark indicates the posterior/ anterior commissure. The third mark indicates the end of the stiff section in the anterior segment of the ring.

The rigid component of the ring is located in the region corresponding to the right ventricular free wall aspect of the annulus and, thus, functions as a remodeling ring in this particular area. Both ends of the ring, however, are completely flexible, with an increased open design that allows 3-dimensional movement and a wider accommodation of the conduction system to reduce iatrogenic injuries. It is important to emphasize that although partial annuloplasty bands can also achieve similar objectives, they lack the rigid fixation of the free wall aspect of the annulus.

The complete implantation technique of a tricuspid ring has been previously described by our group. In brief, a right atriotomy parallel to the atrioventricular groove is performed, and the tricuspid valve is analyzed to identify the dysfunction and note the corresponding lesions (in the setting of functional TR, the dysfunction is type I, secondary to severe annular dilation). The ring size is selected according to the length of the attachments of the tricuspid septal leaflet (intercommisural distance) and the surface area of the anterior leaflet (Figure 2, $A-C$ ).

Because the ring has an exaggerated open design, fewer sutures are required in the membranous septum near conduction tissue. We used interrupted braided 2-0 sutures
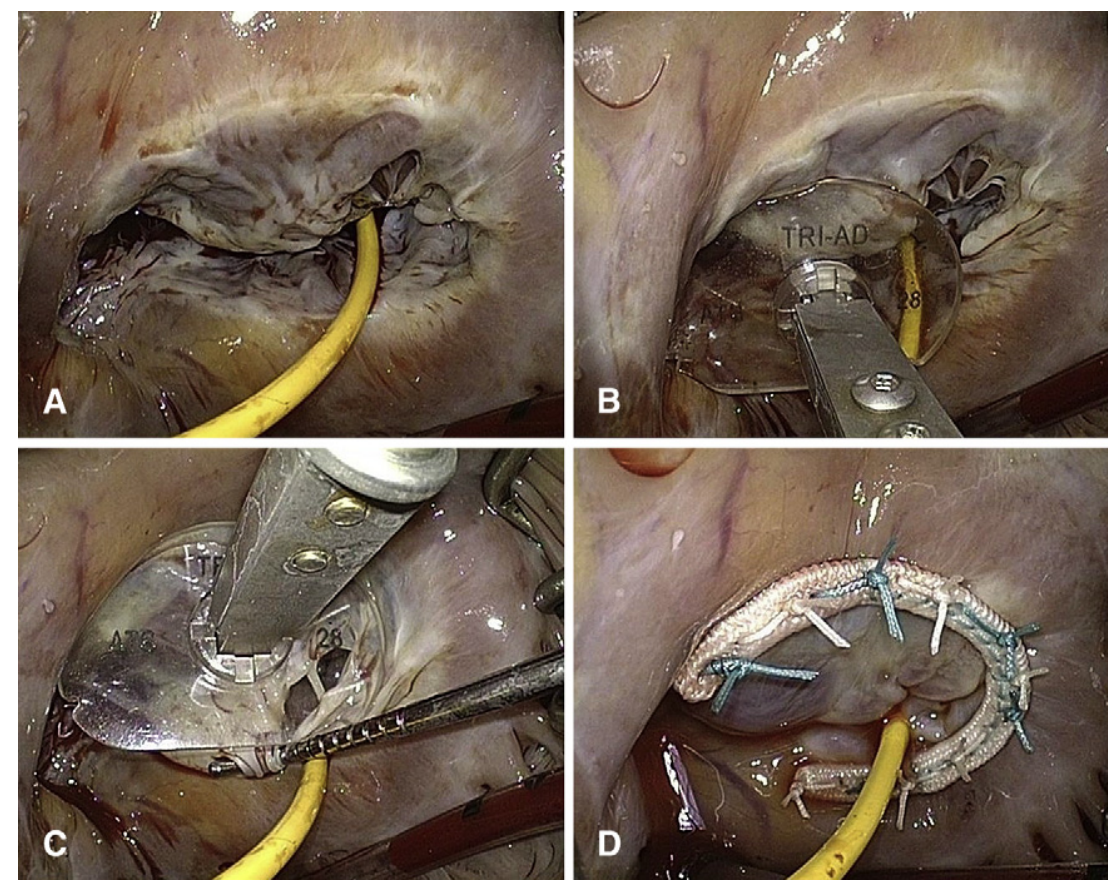

FIGURE 2. A, Tricuspid valve with dilated annulus. B, Tri-Ad ring sizer no. 28. Note the degree of annular dilation in the region of the anteroposterior commissure corresponding to the right ventricular free wall. C, Sizing the annulus to the surface area of the anterior and posterior leaflets. D, Final view demonstrating the competent tricuspid valve after ring implantation. 
for implantation. The sutures are placed approximately 1 $\mathrm{cm}$ from the anterior-septal commissure to approximate to the level of the coronary sinus along the membranous septum. The sutures are then placed through the ring and tied securely (Figure 2,D).

From September to December 2010, 42 patients with degenerative mitral valve disease underwent consecutive concomitant tricuspid valve repair with the Tri-Ad Adams ring. The ring size distribution was $26 \mathrm{~mm}$ in 18 patients $(43 \%), 28 \mathrm{~mm}$ in $12(28 \%), 30 \mathrm{~mm}$ in $10(24 \%)$, and 32 $\mathrm{mm}$ in 2 patients $(5 \%)$. No ring-related operative complications developed. No patient required permanent pacemaker implantation for heart block or sinus syndrome. Predischarge transthoracic echocardiography revealed absent or minimal TR in all patients.

\section{CONCLUSIONS}

The design of the Tri-Ad Adams tricuspid annuloplasty ring combines semirigid (stabilization of the free wall annular aspect) and flexible components (3-dimensional adaptation). Additionally, the new ring has an increased open design to better accommodate the conduction tissue and to spare the placement of sutures at the midportion of the septal leaflet and the anterior-septal commissure. Although our initial data have demonstrated the feasibility and early efficacy of the new design, additional studies are required to determine whether the theoretical advantages of the Tri-Ad Adams ring will yield additional benefits compared with other well-established annuloplasty devices used in tricuspid valve repair. ${ }^{1,4,7}$

\section{References}

1. McCarthy PM, Bhudia SK, Rajeswaran J, Hoercher KJ, Lytle BW, Cosgrove DM, et al. Tricuspid valve repair: durability and risk factors for failure. $J$ Thorac Cardiovasc Surg. 2004;127:674-85.

2. Bonow RO, Carabello BA, Chatterjee K, de Leon AC Jr, Faxon DP, Freed MD, et al. 2008 Focused update incorporated into the ACC/AHA 2006 guidelines for the management of patients with valvular heart disease: a report of the American College of Cardiology/American Heart Association task force on practice guidelines (Writing Committee to revise the 1998 guidelines for the management of patients with valvular heart disease). Endorsed by the Society of Cardiovascular Anesthesiologists, Society for Cardiovascular Angiography and Interventions, and Society of Thoracic Surgeons. J Am College Cardiol. 2008;52:e1-142.

3. Pfannmuller B, Doenst T, Eberhardt K, Seeburger J, Borger MA, Mohr FW. Increased risk of dehiscence after tricuspid valve repair with rigid annuloplasty rings. J Thorac Cardiovasc Surg. Epub 2011 Jul 26.

4. Carpentier A. Cardiac valve surgery-the "French correction." J Thorac Cardiovasc Surg. 1983;86:323-37.

5. Filsoufi F, Salzberg SP, Coutu M, Adams DH. A three-dimensional ring annuloplasty for the treatment of tricuspid regurgitation. Ann Thorac Surg. 2006;81:2273-7.

6. Calafiore AM, Iaco AL, Contini M, Di Mauro M. A single-size band, $50 \mathrm{~mm}$ long, for tricuspid annuloplasty. Eur J Cardiothorac Surg. 2008;34:677-9.

7. Cosgrove DM III, Arcidi JM, Rodriguez L, Stewart WJ, Powell K, Thomas JD Initial experience with the Cosgrove-Edwards annuloplasty system. Ann Thorac Surg. 1995;60:499-503, 494

8. Ton-Nu TT, Levine RA, Handschumacher MD, Dorer DJ, Yosefy C, Fan D, et al Geometric determinants of functional tricuspid regurgitation: insights from 3-dimensional echocardiography. Circulation. 2006;114:143-9. 